[4] Güleç, Gülcan, et al. "Anxiety, depression and coping behaviors with pain in cancer patients who are aware or unaware of their cancer." Ağrı-The Journal of The Turkish Society of Algology 29.3 (2017): 109-116.

Disclosure of Interests: None declared DOI: 10.1136/annrheumdis-2019-eular.8028

\section{AB0917 PATTERN OF SERUM CHOLECALCIFEROL (VITAMIN D3) LEVEL AMONG THE FEMALE IN RELATION TO CLOTHING'S}

Mohammad Abdur Razzaque ${ }^{1}$, Mirza Nurul Karim², Rajat Sanker Roy Biswas ${ }^{3}$, Nazrul Islam ${ }^{4}$, Satyajit Mallick ${ }^{2} .{ }^{1}$ Chittagong Medical College, Medicine, Chittagong, Bangladesh; ${ }^{1}$ Chittagong Medical College, Medicine, Chittagong, Bangladesh; ${ }^{3}$ Chittagong Maa O Shisu Medical College, Medicine, Chittagong, Bangladesh; ${ }^{4} B S M M U$, Rheumatology, Dhaka, Bangladesh

Background: Both clinical and subclinical low level vitamin D is common $^{1}$. Various kinds of health hazard including musculoskletal symptoms are frequently seen among the Vitamin $D$ deficients. It is also not uncommon even in a sunny country. Lack of sun exposure, particularly female using veil may be an important cause.

Objectives: To assess the relationship between using veil and serum vitamin $\mathrm{D}_{3}$ (cholecalciferol) level

Methods: This prospective cross-sectional descriptive study was conducted during July 2017 to June 2018. Patients with common complaints related to lack of Vitamin D (muscle cramp, myalgia, fatigue, bone pain, generalized weakness, difficulty in getting up, climbing stairs and pain in weight bearing joints) were enrolled. Patient having other disease were excluded from study. Serum cholecalciferol was measured for each patient. Race, occupation, educational status, skin complexion, body mass index, sunlight exposure, covering of body with clothing's and use of sunscreen were taken under consideration in final analysis. Correlation of serum cholecalciferol level with different types of veils (Burkha, halve sleeve, full sleeve, quarter sleeve and Hijab) of individual's was analyzed.

Results: A total 79 female patients were enrolled after screening 108. All of them were of multi-ethnic Asian origin. Age distribution of them is 17 to 39 years $34.2 \%, 40$ to 50 years $38 \%, 51$ to 70 years $26.6 \%$ and above 70 years $1.3 \%$. Maximum $(93.7 \%)$ of them were house wife, $91.1 \%$ had no adequate sun exposure and $81 \%$ had no skin exposure to sunlight. Among clothing $79.7 \%$ used Burkha, $5.1 \%$ halve sleeve, $2.5 \%$ full sleeve and 12.7\% quarter sleeve. Among Burkha 28.6\% (18), 55.6\% (35) \& $15.9 \%$ (10) and among quarter sleeve $50 \%$ (5), $40 \%$ (4) \& $10 \%$ (1) had deficient, insufficient \& sufficient vitamin $D$ level respectively while $2(100 \%)$ female with full sleeve and $4(100 \%)$ female with halve sleeve had deficient and insufficient vitamin D level respectively. The cholecalciferol level among the users of veil is shown in Table-1. There was no significant difference between different types of clothing's (Table: 2).

Abstract AB0917 Table 1. Weight, height and Vitamin D level in different types of clothing's.

\begin{tabular}{lcccc}
\hline Type of clothing & & Wt in $\mathrm{Kg}$ & $\mathrm{Ht}$ in $\mathrm{cm}$ & Vit D level (range) in $\mathrm{ng} / \mathrm{ml}$ \\
\hline Burkha & Mean & 68.63 & 150.43 & $(8-40) 23.921$ \\
& $\mathrm{~N}$ & 63 & 63 & 63 \\
Halve sleeve & Std. Deviation & 11.706 & 6.574 & 6.3074 \\
& Mean & 70.75 & 150.50 & $(25-30) 27.000$ \\
Full sleeve & $\mathrm{N}$ & 4 & 4 & 4 \\
& Std. Deviation & 17.500 & 1.000 & 2.4495 \\
& Mean & 64.00 & 145.50 & $(15-19) 17.000$ \\
Quarter sleeve & $\mathrm{N}$ & 2 & 2 & 2 \\
& Std. Deviation & 8.485 & 13.435 & 2.8284 \\
Total & Mean & 63.40 & 150.10 & $(16-38) 23.350$ \\
& $\mathrm{~N}$ & 10 & 10 & 10 \\
& Std. Deviation & 10.834 & 6.437 & 6.7497 \\
& Mean & 67.96 & 150.27 & $(8-40) 23.829$ \\
& $\mathrm{~N}$ & 79 & 79 & 79 \\
& Std. Deviation & 11.790 & 6.488 & 6.2418
\end{tabular}

Abstract AB0917 Table 2. Difference of Vitamin D level in relation to clothing's (ANOVA)

\begin{tabular}{lcccccc}
\hline Gender & & $\begin{array}{c}\text { Sum of } \\
\text { Squares }\end{array}$ & df & $\begin{array}{c}\text { Mean } \\
\text { Square }\end{array}$ & $F$ & $\begin{array}{c}\mathrm{P} \\
\text { value }\end{array}$ \\
\hline Female & $\begin{array}{c}\text { Between } \\
\text { Groups }\end{array}$ & 136.315 & 3 & 45.438 & 1.174 & 0.325 \\
& & & & & & \\
\cline { 2 - 7 } & Within Groups & 2902.568 & 75 & 38.701 & & \\
\hline Total & 3038.883 & 78 & & & & \\
\hline
\end{tabular}

Conclusion: Main source of Vitamin D is sunlight. Proper exposure to sunlight is essential for adequate vitamin $D$ level even in a sunny country. Regarding in vitamin D absorption from sunlight, there may be no difference between Burkha and other covered dressings. Further study needed to have a conclusion.

\section{REFERENCE}

[1] Jones AN, Hansen KE. Recognizing the musculoskeletal manifestations of vitamin D deficiency.J Musculoskelet Med. 2009; 26(10): 389 - 96.

Disclosure of Interests: None declared

DOI: 10.1136/annrheumdis-2019-eular.6726

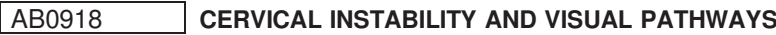 COMPROMISE IN PATIENTS WITH JOINT LAXITY}

sharareh Roshanzamir ${ }^{1}$, Aida Askarian'. ' ${ }^{2}$ Shiraz University of Medical Sciences, Shiraz, Iran (Islamic Republic of); ${ }^{1}$ Shiraz University of Medical Sciences, Shiraz, Iran (Islamic Republic of)

Background: Cervical spine stability is to a great extent dependent on the capsular ligaments, laxity of which would lead to extensive movements of the vertebrae. This instability of the cervical spine, particularly in the upper segments (C0-C2) would be a major source of vertebrobasilar insufficiency. The resultant brain posterior circulation compromise would then make the foundation of white matter changes and cause many neurological signs and symptoms. Occipital lobe and visual pathways are certainly in danger in these circumstances. How and to what extent could the visual pathways be involved in patients with joint laxity is not well studied yet.

Objectives: This study was designed to find whether the visual evoked potential parameters (latency and amplitude) of the patients with generalized joint laxity differs from that of the normal population.

Methods: In this corss-sectional comparative study, 90 consecutive patients with generalized lax joints and 90 normal individuals were enrolled and underwent the visual evoked potential test by pattern reversal. The latency and amplitude of P100 were determind for all the participants and data from the 2 groups were compared statistically.

Results: The results demonstrated that although none of the VEP parameters fell in the abnormal range, there was significant difference between P100 latency in patients with generalized lax joints (mean:110.23 ms) versus normal population $(100.18 \mathrm{~ms}) \quad(\mathrm{P}<0.001)$ with longer latency in patients with generalized lax joints. But the amplitude was not significantly differed across the groups $(P>0.05)$.

Conclusion: It can be concluded from this study that although the VEP parameters of the patients with generalized joint laxity don't exceed the normal range limits, P100 latency in these patients is significantly more prolonged than in normal population. This finding is valuable from two points of view, first P100 latency at the verge of abnormality (upper limit of normal range) in these patients is a warning sign implying the visual pathway involvement, and second VEP could be invaluable in diferentiating the signs and symptomes that are produced by vertebrobasilar insuficiancy secondary to the joint laxity from multiple sclerosis, which can be mimicd both clinically and in MRI findings by many vascular problems but shows a great percent of VEP abnormality as a particular fiture.

\section{REFERENCES}

[1] Steilen D, Hauser R, Woldin B, Sawyer S. Chronic neck pain: making the connection between capsular ligament laxity and cervical instability. The open orthopaedics journal. 2014;8:326-45.

[2] Jaumard NV, Welch WC, Winkelstein BA. Spinal facet joint biomechanics and mechanotransduction in normal, injury and degenerative conditions. Journal of biomechanical engineering. 2011;133:071010.

[3] Siva A. Common Clinical and Imaging Conditions Misdiagnosed as Multiple Sclerosis: A Current Approach to the Differential Diagnosis of Multiple Sclerosis. Neurologic clinics. 2018;36:69-117.

[4] Lin P-C, Chang F-C, Huang H-C, Tsai J-Y, Lin Y-Y, Chung C-P. Greater periventricular white matter hyperintensity severity in basilar artery branch atheromatous disease. BMC neurology. 2017;17:135-.

[5] Kose Ozlece H, Ilik F, Huseyinoglu N. Coexistence of Ehlers-Danlos syndrome and multiple sclerosis. Iranian journal of neurology. 2015;14:116-7.

[6] Pajak M, Majos MA, Szubert W, Stefanczyk L, Majos A. Acute brain ischemia as a complication of the Ehlers-Danlos syndrome, the case series. Vascular. 2014;22:341-5

[7] EL-Cart AK, Mahammoud A, Mahgoub EH. Hypermobility among egyptian childern: prevalence and features. J Rheum 1998; 25(5): 3-5. 